\title{
Techniques for Detecting and Measuring Rip Currents
}

\section{Stephen B Leatherman and Stephen P Leatherman*}

\author{
Department of Earth and Environment, Florida International University, USA
}

\begin{abstract}
A number of techniques have been employed to measure rip currents, but the most accurate ones generally require sophisticated equipment and a boat to retrieve GPS-controlled drifters. A new, simple and inexpensive method involves using a laser rangefinder at the beach to determine rip current speed. The offshore terminus (e.g., seaward extent) was determined for a distance of $100+$ meters at Miami Beach, Florida. Another technique is to aerial image fluorescein tracer dye in a rip current via a drone (e.g, quadcopter) and calculates the speed using ground references. The expense of conducting rip current studies in the past has limited such vital research to a few restricted areas worldwide, which points out the need for cost-effective approaches.
\end{abstract}

\section{Keywords}

Rip speed, Laser rangefinder, Drone imaging, Current drifters, Nearshore currents

\section{Introduction}

Rip currents (also referred to as rips) are narrow areas of seaward-flowing water and represent the greatest hazard at surf beaches worldwide. Researchers have employed a variety of methodologies to identify and measure rip currents, and the purpose of this paper is to review presently used and introduce some new low-cost techniques.

The most common approach, still relied upon by lifeguards for rip identification, is direct observation by the naked eye. The tell-tale signs include a tongue of sediment-laden water moving offshore, seaward movement of floating objects, unusual wave choppiness, and foamy water in the outer edges of the rip head, gap in the breaking waves, and darker water that indicates the presence of a rip channel. Polarizing sunglasses are often used to eliminate water glare, allowing for better observation of differential water coloration. Floating objects such as sticks and oranges, which are neutrally buoyant, can be thrown in the water to detect longshore, rip and tidal currents. Tracer dyes have been used to better delineate rips, especially when the telltale signs are not present or obvious.
Sonu [1] used water-filled polyethylene balls that were adjusted to be neutrally buoyant to detect rip currents. Comparison with dye releases indicated that the movement of the freely-drifting balls represented the mean flow. Nearly-filled plastic jugs of water can be used to locate rips and provide an indication of Lagrangian trajectories [2]. They can be retrieved by attaching a floating neoprene line so as not to cause littering. This low-cost method, which is still used extensively in developing countries, can also provide an estimate of rip speed.

Video cameras have long been used to measure waves and currents at beaches [1]. Beach cams placed a top buildings, high poles or tethered balloons with telephoto lenses aimed at the surf zone have been extensively utilized. Holman and Stanley [3] employed an Argus camera system at the Corps of Engineers Field Research Facility at Duck, North Carolina to obtain time-lapsed photography. Argus camera systems have been utilized to determine the occurrence and persistence of rip currents over time; low-light intensity in the image is associated with areas of non-breaking waves and therefore assumed to represent deep-water rip channels [4].

${ }^{*}$ Corresponding author: Stephen $P$ Leatherman, Department of Earth and Environment, Florida International University, Miami, FL 33199, USA, E-mail: leatherm@fiu.edu

Received: June 13, 2017: Accepted: September 02, 2017: Published: September 04, 2017

Copyright: (C) 2017 Leatherman SB, et al. This is an open-access article distributed under the terms of the Creative Commons Attribution License, which permits unrestricted use, distribution, and reproduction in any medium, provided the original author and source are credited. 
Google Earth and Bing satellite images sometimes show rip channels based on differential water coloration or rips in action as denoted by offshore-flowing sediment plumes.

In recent years, more sophisticated instrumentation has been deployed at rip-prone beaches to measure rip current velocity and flow characteristics. In situ measuring devices include tripod-mounted current meters and pressure sensors. The problem with this Eulerian method of rip measurement is that it involves instrumentation placement-there are concerns that the current meter might not remain in the mean flow area of the rip. There are also logistical problems and safety constraints of installation in a dangerous location [5]. Finally, there are a number of different types of rip currents, which could require different instrumentation for field studies $[6,7]$.

Rip float experiments (e.g., using human drifters) have been conducted in Australia, wherein a person floating freely in the rip current is tracked by theodolites [8] or more recently GPS technology. Lagrangian methods of measuring rip currents have recently become popular $[9,10]$. These methods such as GPS-instrumented drifters have the advantage of less set-up time, safer deployment, more mobility and can capture the path of the rip current. GPS drifters have been extensively used by MacMahan, et al. [11] to measure rip current velocity at beaches in California, France and Australia. Generally, five or more GPS drifters are released in a rip current and tracked in real-time by observers on the beach using laptop computers. Real-time differential GPS drifters have an accuracy less than 1 meter after carrier phase post-processing [12]. Non-differential GPS units, which are an order of magnitude less expensive, are now being used to study rip currents with much success [13].

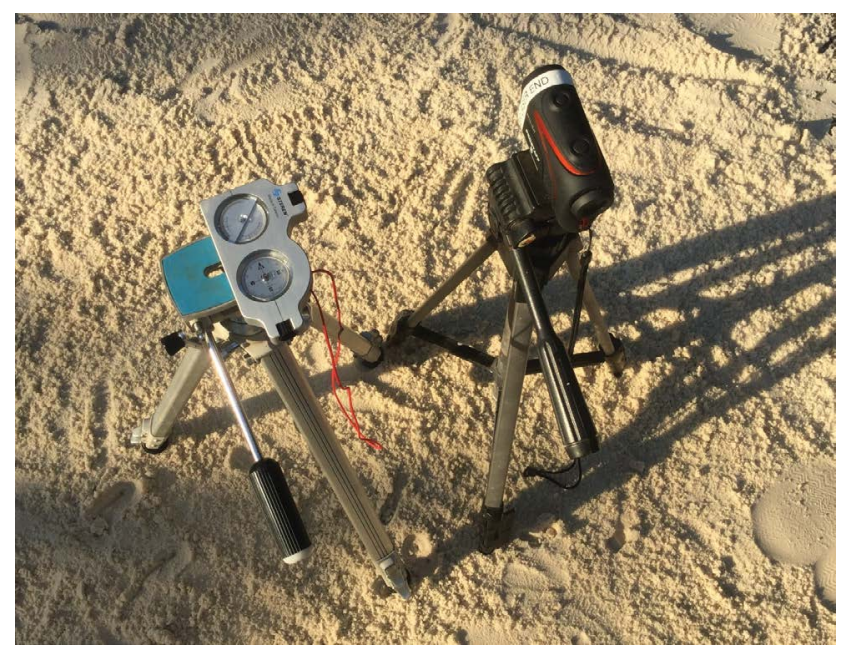

Figure 1: The Nikon Prostaff 7 Laser Rangefinder and Steren Electronics compass are mounted on photographic tripods to measure the speed and path of a rip current, respectively.

\section{Methodology}

\section{Laser rangefinder}

Laser rangefinders are extensively used in the construction industry because of their small size, low cost and high accuracy for measuring distances. Laser rangefinders cannot image water as there is no return, but this hand-held device can bounce a laser beam off any object and determine the laser travel time instantly and hence the distance to the object. There are many options available when choosing a laser rangefinder; prices range from approximately $\$ 100$ to $\$ 300$. The optimal laser rangefinder would have a built-in compass, which exists for the Uineye Laser Rangefinder, but this unit is no longer available for purchase.

A Nikon Prostaff 7 laser rangefinder and a Steren Electronics compass mounted on inexpensive photographic tripods were used to determine the position and path of floating objects in currents (Figure 1). The Prostaff 7 model, which costs $\$ 300$, has an accuracy of $0.1 \mathrm{~m}$ up to a distance of 540 meters according to the manufacturer. This model does not have the means to attach to a tripod so an adhesive camera mount was attached to the bottom. The Steren Electronics compass is a low-cost device $(\$ 100)$ which was used to measure the horizontal angle for non-linear flow paths in combination with a laser rangefinder.

Rip current measurements were conducted on July 18, 2016 at South Beach in Miami, Florida using the laser rangefinder [14]. An assistant floating in the rip current was used as a target for the laser rangefinder. The rip current moved in a relatively straight path as delineated by the fluorescein tracer dye so that the compass was not necessary. The assistant followed the leading edge of the tracer dye as it was pulled seaward by the rip current. Incoming waves knocked the assistant back intermittently so that he sometimes had to paddle to catch up to the leading edge of the tracer dye. The rangefinder measurements showed an average rip speed of $0.4 \mathrm{~m} / \mathrm{s}$ (Table 1 ), which corresponded well with simultaneously-obtained GPS drifter measurements [14].

Table 1: Rip current speed measurements taken with the laser rangefinder on July 18, 2016 at South Beach show an average rip speed of $0.4 \mathrm{~m} / \mathrm{s}$. Measurements were also taken by this technique at many other times as detailed in Leatherman (2017) [14].

\begin{tabular}{|l|l|l|}
\hline Seconds & Distance $(\mathbf{m})$ & Speed $(\mathbf{m} / \mathbf{s})$ \\
\hline 0 & 68 & \\
\hline 18 & 73 & 0.3 \\
\hline 9 & 75 & 0.2 \\
\hline 9 & 78 & 0.3 \\
\hline 7 & 81 & 0.4 \\
\hline 5 & 84 & 0.6 \\
\hline 13 & 90 & 0.5 \\
\hline 11 & 92 & 0.2 \\
\hline 21 & 101 & 0.4 \\
\hline
\end{tabular}


Table 2: The laser rangefinder in conjunction with the compass allow for measuring a non-linear rip path with an accuracy of $0.1 \mathrm{~m}$.

\begin{tabular}{|l|l|l|l|l|l|l|l|}
\hline Point & $\begin{array}{l}\text { Compass angle } \\
\text { reading }\end{array}$ & $\begin{array}{l}\text { Referenced } \\
\text { angle }\end{array}$ & $\begin{array}{l}\text { Angle } \\
\text { (Radians) }\end{array}$ & $\begin{array}{l}\text { Laser rangefinder } \\
\text { distance }\end{array}$ & $\begin{array}{l}\text { Leg distance } \\
\text { (Calculated) }\end{array}$ & $\begin{array}{l}\text { Rip path } \\
\text { distance } \\
\text { (Calculated) }\end{array}$ & $\begin{array}{l}\text { Tape distance } \\
\text { (Actual) }\end{array}$ \\
\hline 1 & 334 & 0 & 0 & 4.9 & 49 & 49 & 5 \\
\hline 2 & 334 & 0 & 0 & 8 & 3.1 & 8 & 8 \\
\hline 3 & 334 & 0 & 0 & 11.1 & 3.1 & 11.1 & 11 \\
\hline 4 & 335 & 1 & 0.017 & 12.9 & 1.81 & 12.91 & 13 \\
\hline 5 & 335 & 0 & 0.000 & 14.9 & 2.00 & 14.91 & 15 \\
\hline 6 & 339 & 4 & 0.070 & 17.9 & 3.21 & 18.12 & 18 \\
\hline 7 & 343.5 & 4.5 & 0.079 & 20.3 & 2.83 & 20.95 & 21 \\
\hline 8 & 344.5 & 1 & 0.017 & 21.2 & 0.97 & 21.92 & 22 \\
\hline 9 & 348.5 & 4 & 0.070 & 23.8 & 3.04 & 27.96 & 25 \\
\hline 10 & 353 & 4.5 & 0.079 & 26.1 & 3.02 & 30.10 & 28 \\
\hline 11 & 355 & 2 & 0.035 & 28 & 2.12 & 32.07 & 32 \\
\hline 12 & 357 & 2 & 0.035 & 29.7 & 1.98 & 32 \\
\hline
\end{tabular}

The Steren Electronics compass can be used to more accurately determine the rip path distance and therefore the speed in cases where the rip current is deflected by the longshore current. A "dry run" test was performed to determine the accuracy of using the compass in conjunction with the laser rangefinder for an arcing rip current. A 32-meter tape measure was laid out in a curved path representing the path of a rip current, and 12 markers, representing measurements points, were placed along the path at varying distances. The laser rangefinder was used to measure the distance to each marker and a compass to determine the angle between adjacent markers. Using the law of cosines, the distance between each marker was calculated and compared to the true tape measure distance to determine accuracy. The results showed that the laser rangefinder in conjunction with the compass was accurate to about $0.1 \mathrm{~m}$ for this experiment (Table 2).

\section{Drone imaging of tracer dye}

Quadcopters, which are a type of drone, are now being used for field surveying in many areas. Drone usage is rapidly increasing for coastal monitoring, and there are many examples of rip current video, but most observations have been qualitative and not for scientific purposes. Drones are especially useful for studying rip currents (www.ripcurrents. com) adjacent to shore-perpendicular, coastal engineering structures (e.g., groins and jetties) and in high-energy wave environments where large breaking waves cause dangerous conditions.

Tracer dyes have long been utilized by scientists and medical doctors for water movement indicators and blood flow markers in the human body, respectively. Dye releases have been used in rip currents for many years, primarily for visual purposes to illustrate offshore-flowing currents for scientific studies and/or educational videos (see science of the surf and www.ripcurrents.com).

Coastal scientists use several dyes for water tracer studies, especially fluorescein, potassium permanganate, and rhodamine, but fluorescein dye is the only one that

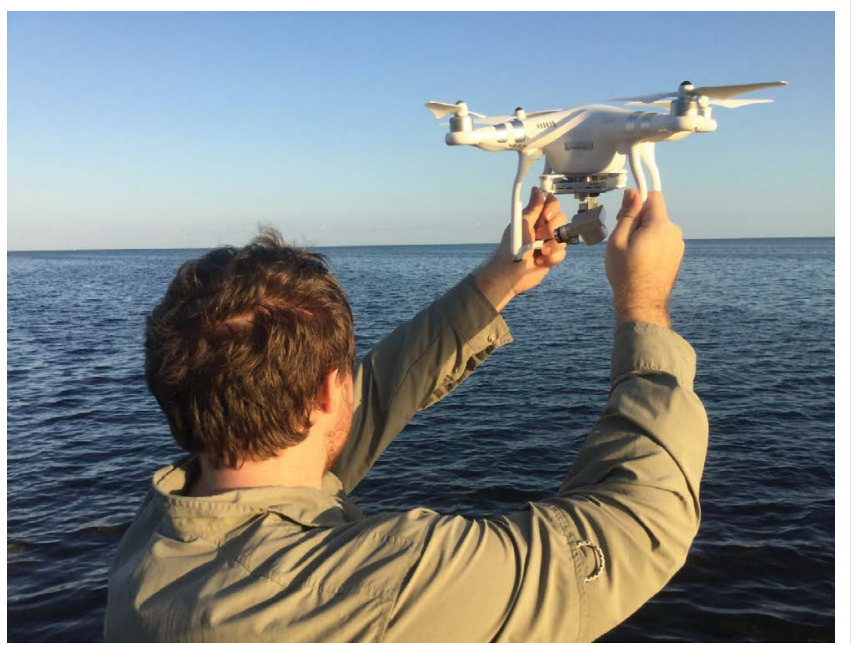

Figure 2: The DJI Phantom 3 Advanced Quadcopter is being prepared for takeoff.

has been shown by the US. Environmental Protection Agency to be safe in the marine environment. Fluorescein dye is non-toxic, biodegradable, and NSF approved as safe in drinking water (see Material Safety Data Sheet for fluorescein, disodium salt; www.hazard.com/msds). This liquid fluorescein tracer dye costs $\$ 80$ per gallon for the lowest grade-higher grades are not necessary for this application. Larger quantities can be obtained at lower unit cost from manufacturers.

A DJI Phantom 3 Advanced quadcopter (which costs about \$1000; Figure 2) equipped with a high definition, gimbal-stabilized video camera was used to trace a plume of fluorescein tracer dye carried seaward by the bar-gap rip current at South Beach, Florida on January 12, 2017 (Figure 3). This weak rip, field-determined to have a speed of only 0.1 meters per second, was generated by a 15 knot East wind and 0.6-meter spilling breakers with a 5 -second wave period.

Drones are especially useful where drifters are difficult to deploy. Drones provide an aerial view of the rip in motion as delineated by the tracer dye, and can also be 
used to determine rip speed when reference points with known positions are imaged as was undertaken at Ocean Reef Park in Palm Beach County, Florida. The speed of the rip current was determined by calculating the rate that the dye traveled across the natural rock outcropping, which involve demploying ESRI ArcMap GIS software. This structurally-controlled rip current that occurred on April 27, 2016 traveled 100 meters offshore with an average speed of 0.4 meters per second [14].

\section{Discussion}

The laser rangefinder can image any floating object, has the advantage of being much less expensive than GPS drifters and does not risk instrument loss. Differential GPS instrumentation can cost thousands of dollars per drifter, albeit Johnson, et al. [15] noted that DGPS drifters can be built for $\$ 500$. Considerable time is also required to process the digital GPS data especially if multiple drifters, georeferencing or bathymetry are included. Instrument retrieval requires a boat so that the total cost for a deployment can be expensive and time consuming.

The laser rangefinder is hand-held so the operator can be affected by the wind. A fairly steady onshore wind of $15-20 \mathrm{kts}$ was not a problem, but the $30 \mathrm{kt}$ wind on another occasion caused problems in holding the rangefinder steady in order to consistently hit the target. A tripod to steady the rangefinder solved this problem. The GPS drifter often served as the target for the laser rangefinder.

There can be difficulty hitting a small target at long distances with a laser rangefinder so a larger target like a human drifter can be employed. Tracer dye can also be used to assure that the person is keeping adrift with the current. South Florida rip currents rarely extend more than 100 meters offshore so there was no problem in hitting the target with the laser rangefinder [14]. For mega-rips as documented in Australia and California [16], flow measurements along the full extent of the rip may not be possible.

The drone and tracer dye technique has the advantage of the aerial perspective to delineate the full path of the rip current. Videos of rips in action are very useful to study flow characteristics and to visualize currents for public recognition in order to promote beach safety. This method is especially useful for detecting flash rip currents which are present during confused sea conditions which make them very difficult to detect. Speed measurements can be determined by timing the tracer dye as it moves in the rip current relative to ground references. Freeze frames from the drone video can be distorted, but this measurement error can be minimized by positioning the drone directly above the field of view.

Drone operation and placement of fluorescent tracer dye in the water must be cleared with lifeguards and local officials at recreational beaches. Safety concerns for large crowds at Miami Beach greatly restricted drone deploy-

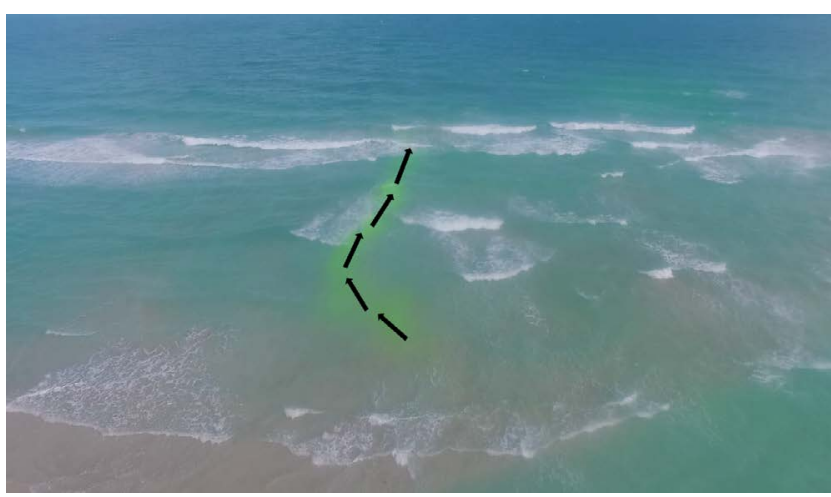

Figure 3: A weak rip current is delineated by fluorescein tracer dye and imaged by a DJI Phantom 3 Advanced Quadcopterat Miami Beach on January 12, 2017.

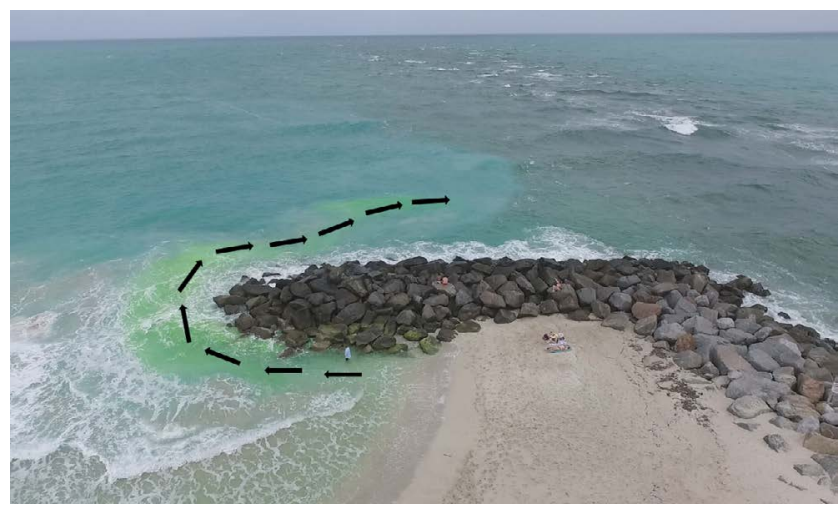

Figure 4: A structurally-controlled rip current at Haulover Park jetty can feed into a dangerous tidal current.

ment so that only a very weak rip current was imaged (Figure 3) on a cold, blustery day when few people were at the beach. Rip currents that feed into a tidal current at Haulover Inlet in Miami-Dade County, Florida are especially dangerous because the flood tidal current will carry victims into the inlet channel with boaters or far offshore with the ebbing current (Figure 4) [14].

High winds at the beach can interfere with drone takeoffs and landings. In these situations, the preferred takeoff method is to have an assistant hold the drone above his head while the drone operator rapidly accelerates the drone upwards (Figure 2). When landing the drone in high wind speed conditions, quick landing and recovery of the drone is necessary so that sand entering the motors and camera is minimal. A launch pad may be useful.

\section{Conclusions}

The relatively new methods of using a laser rangefinder and aerial drone video with tracer dye provide cost-effective techniques of measuring rip currents. This instrumentation is mobile, can be rapidly deployed and requires a crew of only two people to operate. These methods separately or in concert can greatly increase our understanding of rip current flow characteristics, especially in dangerous and inaccessible areas, such as near jetties and groins. 


\section{References}

1. Sonu CJ (1972) Field observation of nearshore circulation and meandering currents. Journal of Geophysical Research 77: 3232-3247.

2. Inman D, Zampol J, White T, Hanes D, Waldorf B, et al. (1980) Field measurements of sand motion in the surf zone. Coastal Engineering Proceedings 1: 1215-1234.

3. Holman RA, Stanley J (2007) The history and technical capabilities of ARGUS. Coastal Engineering 54: 477-491.

4. Prodger S (2012) Argus observations of rip current variability along a macro-tidal beach. Master's Thesis for the University of Plymouth 61.

5. Brander RW, Short AD (2000) Morphodynamics of a largescale rip current system at Muriwai Beach, New Zealand. Marine Geology 165: 27-39.

6. Leatherman SP (2013) Rip currents. In: Finkl CW, Coastal Hazards, Coastal Research Library. Springer, 6: 811-831.

7. Castelle B, Scott T, Brander RW, McCarroll RJ (2016) Rip current types, circulation and hazard. Earth-Science Reviews 163: 1-21.

8. Short AD, Hogan CL (1994) Rip currents and beach hazards: their impact on public safety and implications for coastal management. Journal of Coastal Research 12: 197-209.

9. McCarroll RJ, Brander R, MacMahan JH, Sherker S (2014) Evaluation of swimmer-based rip current escape strategies. Natural Hazards 71: 1821-1846.
10. Scott T, Austin M, Masselink G, Russel P (2016) Dynamics of rip currents associated with groynes-field measurements, modelling, and implications for beach safety. Coastal Engineering 107: 53-69.

11. MacMahan JH, Brown J, Brown J, Thorton E, Reniers A, et al. (2010) Mean Lagrangian flow behavior on an open coast rip-channeled beach: A new perspective. Marine Geology 268: 1-15.

12. Schmidt WE, Woodward BT, Millikan KS, Guza RT, Raubenheimer B, et al. (2003) A GPS-tracked surf zone drifter. Journal of Atmospheric and Oceanic Technology 20: 1069-1075.

13. Sabet BS, Barani GA (2011) Design of small GPS drifters for current measurements in the coastal zone. Ocean and Coastal Management 54: 158-163.

14. Leatherman SB (2017) Rip current measurements at three south florida beaches. Journal of Coastal Research 33: 1228-1234.

15. Johnson D, Stocker R, Head R, Imberger J, Pattiaratchi $C$ (2003) A compact, low-cost GPS drifter for use in the oceanic nearshore zone, lakes, and estuaries. Journal of Atmospheric and Oceanic Technology 20: 1880-1884.

16. Brander RW, MacMahan JH (2011) Future challenges for rip current research and outreach. In: Leatherman SP, Fletemeyer J, Rip Currents: Beach Safety, Physical Oceanography, and Wave Modeling. Boca Raton, CRC Press, Florida, 1-29. 